\title{
Removal of Formaldehyde from Synthetic Wastewater Using Natural and Modified Zeolites
}

\author{
Dainius Paliulis \\ Department of Environmental Protection, Vilnius Gediminas Technical University, \\ Sauletekio al. 11, LT-10223 Vilnius, Lithuania
}

Received: 13 October 2015

Accepted: 9 November 2015

\begin{abstract}
Chemically modified and natural zeolite consisting of clinoptilolite and mordenite minerals (Sokirnica Mine, Ukraine) was selected for testing the adsorption ability of formaldehyde. Modified zeolite was produced from natural zeolite by chemical activation with sulphuric acid $\left(\mathrm{H}_{2} \mathrm{SO}_{4}\right) 2 \mathrm{M}$ at $95-98^{\circ} \mathrm{C}$ for six hours. Synthetic wastewater was prepared by adding formaldehyde at concentrations equal to or higher than the maximum allowable concentration (MAC) values: $1 \mathrm{MAC}=2 \mathrm{mg} / 1,2 \mathrm{MAC}=4 \mathrm{mg} / 1,3 \mathrm{MAC}=6 \mathrm{mg} / \mathrm{l}, 5$ $\mathrm{MAC}=10 \mathrm{mg} / \mathrm{l}$, and $10 \mathrm{MAC}=20 \mathrm{mg} / \mathrm{l}$. The effects of adsorption time $(5 \mathrm{~min}, 10 \mathrm{~min}, 30 \mathrm{~min}, 60 \mathrm{~min}$, $3 \mathrm{~h}, 5 \mathrm{~h}, 8 \mathrm{~h}$, and $12 \mathrm{~h}$ ) were examined for the selected formaldehyde concentrations. Adsorption efficiency, adsorption capacity, and iodine numbers were evaluated for the selected adsorbents. The positive effect of natural zeolite chemical modification was obtained in the range of 5.4 to $24.0 \%$, with an average value of $9.2 \%$. Iodine number was selected as a parameter for natural zeolite chemical modification with $2 \mathrm{M}$ sulphuric acid evaluation. The iodine number before sorption was $154.3 \mathrm{mg} \cdot \mathrm{g}^{-1}$ and after modification was $164.5 \mathrm{mg} \cdot \mathrm{g}^{-1}$.
\end{abstract}

Keywords: formaldehyde, natural zeolite, modified zeolite, wastewater, adsorption

\section{Introduction}

Formaldehyde is one of the most dangerous industrial wastewater organic components. According to a report on carcinogens, formaldehyde is the $25^{\text {th }}$ most produced chemical in the U.S. with more than 5 million tons produced each year. Formaldehyde is a toxic organic compound listed among the 45 organic substances that pose concerns for environmental impact [1]. Various industries such as synthetic resin production, aquaculture industry, adhesive

$\overline{\text { *e-mail: dainius.paliulis@vgtu.lt }}$ and glue manufacturing, disinfectant and preservative production, chemical and petrochemical industry, textile processing, paper manufacturing, and wood processing use formalin in aqueous solution consisting of approximately $37 \%$ formaldehyde [1]. Industries that produce or utilize formaldehyde usually generate wastewater containing variable concentrations of this compound, ranging from a few to hundreds of milligrams per litre. Due to its wide application across the world, there is a potential to release a large amount of formaldehyde annually into the environment through industrial effluents. Wastewaters containing this substance are required to be treated in an effective and environmentally friendly process before the 
wastewater can be discharged into the environment [2].

Wastewater treatment may include mechanical, biological, and physical-chemical methods. Selection of a wastewater treatment method depends on pollutant origin. One wastewater treatment using physical-chemical methods is adsorption, which has the advantages of being fast, cheap, and universal [3]. For removing organic pollutants from water, different low-cost materials are used as adsorbents, including agricultural products, industrial wastes [4], bentonite [5], human hair, sheep wool [6], and activated carbon [7], etc.

Different treatment methods of wastewater contaminated with formaldehyde are used in practice: oxidation [1, 8], membrane separation [9], electrocoagulation [10], and adsorption [11, 12]. Currently a high number of experimental studies where natural, modified, or synthetic adsorbents used for removal of heavy metals from water are carried out, but there is still not enough data about adsorbent usage for removing organic compounds (e.g., formaldehyde) from water. Sorbents are insoluble substances that attach to and keep pollutants in their molecular structure (absorbents) or in their porous and capillary surface (adsorbents) [13].

Zeolite is one of the most popular natural adsorbents with valuable physicochemical properties, such as high cation exchange capacity (CEC), cation selectivity, and high void volume. The use of zeolite minerals in environmental applications is gaining increasing interest mainly due to their properties and the simplicity of its modification [14]. Zeolite is a natural aluminosilicate [15]. Zeolite consists of various oxides: $\mathrm{Al}_{2} \mathrm{O}_{3}, \mathrm{TiO}_{2} \mathrm{Fe}_{2} \mathrm{O}_{3}, \mathrm{MgO}, \mathrm{CaO} \mathrm{Na}_{2} \mathrm{O}$, $\mathrm{K}_{2} \mathrm{O}$, and $\mathrm{H}_{2} \mathrm{O}$ [16], with the main part consisting of $\mathrm{SiO}_{2}$.' According to [15], zeolites are ecologically clean, inert, and non-toxic materials. However, not all of the adsorbents have sufficient adsorptive capacity in the natural state [17]. Natural zeolites were adopted for the removal of heavy metals [18] and ammonium [19], and for the adsorption of $\mathrm{Ba}^{2}+$ ions as well as sulphate ions [20]. One natural zeolite (i.e., clinoptilolite) has thermo and chemical stabilityefficient adsorption, ion exchange, and catalyst properties. The pore size is in the range of $0.45-0.6 \mathrm{~nm}$. These pores are highly effective in ion exchange reactions [21]. Adsorbents are characterized by high adsorptive capacity, good selectivity, easy regeneration, mechanical strength of particles, filtration capacity, and catalytic activity [17]. Synthetic sorbents usually are more efficient than natural sorbents [22], which are activated or modified in order to acquire the appropriate physical-chemical, catalytic, and adsorptive properties. The following activation methods have found wide application: thermal and hydrothermal treatment, and treatment with chemical substances $[17,23]$. In the present research, adsorption efficiency, adsorption capacity, and iodine number were evaluated for the natural zeolite (Sokirnica Mine, Ukraine) and chemically modified natural zeolite.

The aim of this work was to compare the usage of natural and chemically modified zeolites for removing formaldehyde from wastewater and to determine the impact of different contact times at different concentrations.

\section{Materials and Methods}

\author{
Materials
}

In this work, natural zeolite (Sokirnica Mine, Ukraine) and chemically modified natural zeolite were used for formaldehyde removal from wastewater.

\section{Determination of Dry Bulk Density}

Determination of dry bulk density is based on dry matter weight and the occupied volume ratio using a standard measuring container (ISO 567:1995. CokeDetermination of bulk density in a small container). This experiment was carried out with a fraction of adsorbent with diameter in the range 1-2 $\mathrm{mm}$. Dry bulk density is inversely related to porosity of adsorbent; the lower the dry bulk density value the more porous the adsorbent is.

\section{Adsorbent Modification}

The adsorbent was mixed with $2.0 \mathrm{M}$ solution of sulphuric acid in the ratio mineral: reagent $(1: 4 \mathrm{~W}: \mathrm{V})$, and heated at $95-98^{\circ} \mathrm{C}$ for 6 hours. Then it was washed with deionized water to neutral $\mathrm{pH}$ and filtered. The precipitate was dried at $105^{\circ} \mathrm{C}$ to constant weight [24].

\section{Adsorption Capacity Evaluation}

Adsorption capacity and iodine number were selected for evaluation of natural zeolite and chemically modified zeolite. An iodine number was estimated by mixing $200 \mathrm{mg}$ of the adsorbent with $0.02 \mathrm{~N}$ iodine solution, shaken occasionally, left overnight, and then estimated by titration against standard $\mathrm{Na}_{2} \mathrm{~S}_{2} \mathrm{O}_{3}[25]$.

\section{Effect of Initial Concentration on Formaldehyde Removal}

Recommended $\mathrm{pH}$ values of the treated wastewater range from 6.5 to 8.5 . For that reason the solutions were prepared with a $7.0 \mathrm{pH}$ solution. $\mathrm{pH}$ was measured with a Mettler Toledo Seven Multi pH meter. 0.1 $\mathrm{M} \mathrm{NaOH}$ and $0.1 \mathrm{M} \mathrm{HNO}_{3}$ were used to adjust $\mathrm{pH}$.

The maximum allowable concentration (MAC) of formaldehyde in wastewater, which is allowed to discharge to surface waters, is $2.0 \mathrm{mg} / \mathrm{l}$ (regulation on wastewater management, Official Gazette, No. 110-4522, 2007). Therefore, in the present research we selected concentrations of formaldehyde equal to or higher than the MAC values: $1 \mathrm{MAC}=2 \mathrm{mg} / \mathrm{l}, 2 \mathrm{MAC}=4 \mathrm{mg} / \mathrm{l}, 3$ $\mathrm{MAC}=6 \mathrm{mg} / \mathrm{l}, 5 \mathrm{MAC}=10 \mathrm{mg} / \mathrm{l}$, and $10 \mathrm{MAC}=20 \mathrm{mg} / \mathrm{l}$. The experiments of static formaldehyde adsorption from aqueous solution are performed by mixing an adsorbent sample with the formaldehyde concentration solution on a 1:100 ratio of adsorbent and solution mass (i.e., $1 \mathrm{~g}$ of adsorbent and $100 \mathrm{ml}$ of aqueous solution) using capped bottles $(100 \mathrm{ml})$. The suspensions were filtered thorough a $0.45 \mu \mathrm{m}$ glass filter and the concentration of formaldehyde 
in the filtrates as well as in the initial solutions was determined by applying the photocolorimetric method measuring optical density at $\lambda=584 \mathrm{~nm}$ in $1 \mathrm{~cm}$ length cells. Also, formaldehyde was determined in the blank solution to adjust possible contamination of chemical reagents.

\section{Effect of Sorption Time on Removal of Formaldehyde}

The sorption time is assessed by analysing the static formaldehyde sorption from the aqueous solution. The aim of these experiments was to determine the time when the balance of adsorption is achieved. Durations of $5 \mathrm{~min}, 10 \mathrm{~min}, 30 \mathrm{~min}, 60 \mathrm{~min}, 180 \mathrm{~min}, 300 \mathrm{~min}, 480$ min, and $720 \mathrm{~min}$ were selected for adsorption research. The samples were placed on an A. C. Gerhardt $\mathrm{GmbH}$ \& Co.KG Rotoshake RS12 elution shaker and shaken at room temperature of $20-22^{\circ} \mathrm{C}$. Batch studies were used to determine the equilibrium time for the adsorption of formaldehyde by adsorbent. All samples with $1 \mathrm{~g}$ of adsorbent were added to the formaldehyde solution at the same $\mathrm{pH}$ (7.0) and shaken for the above-mentioned period of time. The samples were filtered (using glass filter with $0.45 \mu \mathrm{m}$ pores) and the filtrate formaldehyde concentrations were measured.

\section{Statistical Analysis}

Each analysis was prepared and analyzed in triplicate. The average of the results and standard deviations values were calculated.

\section{Results and Discussion}

\section{Characterization of the Adsorbent}

Natural zeolites are widely used adsorbents due to their resistance to aggressive media, and their selectivity of alkali, alkaline earth, and some heavy metal cations [14]. The wide usefulness of zeolite is a result of their ion exchange and adsorption properties, and high chemical and mechanical stability. The chemical composition of the chosen adsorbent is (\%): $\mathrm{SiO}_{2}-71.5, \mathrm{Al}_{2} \mathrm{O}_{3}-13.1$, $\mathrm{Fe}_{2} \mathrm{O}_{3}-0.9, \mathrm{TiO}_{2}-0.2, \mathrm{CaO}-2.1, \mathrm{MgO}-1.07, \mathrm{P}_{2} \mathrm{O}_{5}-0.03$, $\mathrm{K}_{2} \mathrm{O}+\mathrm{Na}_{2} \mathrm{O}-5.03$, F-0.025, As-0.002, $\mathrm{Pb}-0.002$, and $\mathrm{Cu}-0.002$ [15]. The quantity of trace elements in natural zeolite is (g/t): Mn-242, Zn-45, Ga-20, Th-12, Rb-110, $\mathrm{Y}-22, \mathrm{Zr}-235, \mathrm{Nb} 22$, and $\mathrm{Ba}-232$ [15]. The chemical nature and pore structure usually determines sorption activity. The main physico-chemical properties of the natural zeolite are listed in Table 1. Natural zeolite consists of $90 \%$ clinoptilolite, and the other part consists of mordenite (up to $10 \%$ ). Clinoptilolite's chemical formula is $\left(\mathrm{K}_{2}, \mathrm{Na}_{2}, \mathrm{Ca}\right)_{3} \cdot \mathrm{Al}_{6} \mathrm{Si}_{30} \mathrm{O}_{72} \cdot 21 \mathrm{H}_{2} \mathrm{O}$. Mordenite's chemical formula is $\left(\mathrm{Na}_{2}, \mathrm{Ca}\right)_{4} \cdot \mathrm{Al}_{8} \mathrm{Si}_{40} \mathrm{O}_{96} \cdot 28 \mathrm{H}_{2} \mathrm{O}$ [26]. The exact chemical formula of natural zeolite depends on mine place.

\section{Evaluation of Dry Bulk Density}

A 1-2 mm fraction of adsorbent was chosen for experimental research. Sorption of ammonium depends on sorbent fraction. According to Croatian scientists [27], a fraction in the range of 1-2 $\mathrm{mm}$ was the most effective. The value of zeolite dry bulk density was $0.87 \pm 0.05 \mathrm{~g} / \mathrm{cm}^{3}$.

\section{pH Evaluation}

$\mathrm{pH}$ is one of the most important parameters controlling the adsorption process [28]. The effect of the $\mathrm{pH}$ of the solution on the adsorption of formaldehyde on natural zeolite was determined. The $\mathrm{pH}$ of the solution was controlled by the addition of $0.1 \mathrm{M} \mathrm{NaOH}$ and $0.1 \mathrm{M} \mathrm{HNO}_{3}$. According to surface wastewater management regulation requirements (by order of the minister of the environment, No. D1-193 (Official Gazette, 2007, No. 42-1594) wastewater discharged to the environment must have a $\mathrm{pH}$ within the range 6.5-8.5. Experiments were carried out with different solutions of $\mathrm{pH}$ : 1.0, 3.0, 5.0, 7.0, and 8.5. However, according to preliminary experimental results no significant effect of $\mathrm{pH}$ on formaldehyde sorption was determined. Therefore, $\mathrm{pH} 7.0$ was used for testing both natural and modified zeolite.

\section{Effect of Contact Time, Initial Formaldehyde Concentration, and Zeolite Modification}

The experimental results of adsorptions at various formaldehyde concentrations $(2-20 \mathrm{mg} / \mathrm{l})$ with different contact times ( $5 \mathrm{~min}, 10 \mathrm{~min}, 30 \mathrm{~min}, 60 \mathrm{~min}, 180 \mathrm{~min}, 300$ min, $480 \mathrm{~min}, 720 \mathrm{~min}$ ) in $\mathrm{pH} 7$ solution are presented in Figs. 1-5. Concentration of formaldehyde in solution was determined by applying the photocolorimetric method.

As can be seen in Fig. 1, formaldehyde sorption efficiency of modified zeolite is higher than natural zeolite. The highest efficiency in $2 \mathrm{mg} / \mathrm{l}$ formaldehyde solution was after 12 hours $(95.0 \%)$. To compare it with natural unmodified zeolite sorption efficiency $(84.5 \%)$, it can be seen that modified zeolite is more effective than

Table 1. Main physical properties of used natural zeolite [15].

\begin{tabular}{|c|c|}
\hline Porosity & $34 \%$ \\
\hline Density & $2.370 \mathrm{~kg} / \mathrm{dcm}^{3}$ \\
\hline Radionuclides activity to & $144.5 \mathrm{Bg} / \mathrm{kg}$ \\
\hline Specific surface & about $144 \mathrm{~m}^{2} / \mathrm{g}$ \\
\hline Mechanical strength, compressive & $150 \mathrm{~kg} / \mathrm{cm}^{2}$ \\
\hline Clinoptilolite up & $90 \%$ \\
\hline Abrassion up & $4 \%$ \\
\hline CEC & $1.5 \mathrm{mg} \cdot \mathrm{ekv} / \mathrm{g}$ \\
\hline Humidity & $4 \%$ \\
\hline
\end{tabular}


the natural one. Modification of natural zeolite positively affected sorption capacity of natural zeolite [23]. Chemical and thermal treatments of zeolite result in cation migration and thus affect the cation location and pore opening [22]. Fig. 2 shows a tendency for sorption efficiency to be higher when zeolite is modified with sulphuric acid in $4 \mathrm{mg} / \mathrm{l}$ formaldehyde solution. After 12 hours, when sorption efficiency was highest, modified zeolite reached $73.0 \%$ efficiency, and natural zeolite $68.5 \%$ efficiency. Therefore, modification of natural zeolite increased sorption efficiency.

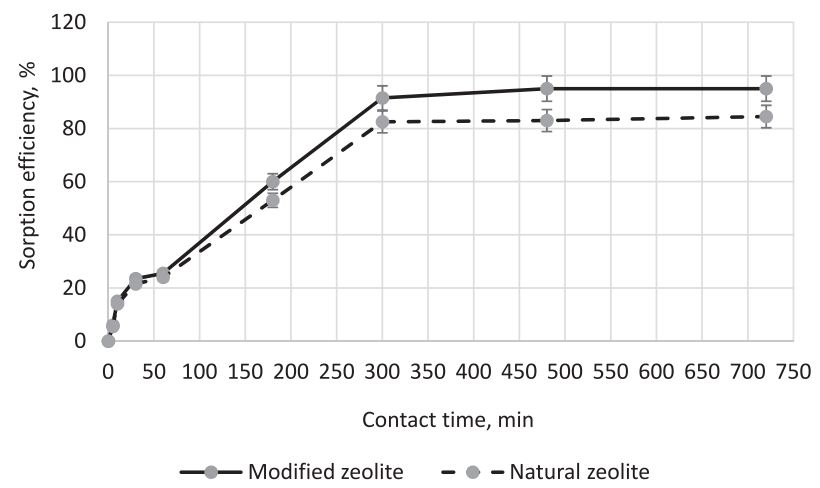

Fig. 1. Sorption efficiency comparison between natural and modified zeolite in $2 \mathrm{mg} / \mathrm{l}$ formaldehyde solution.

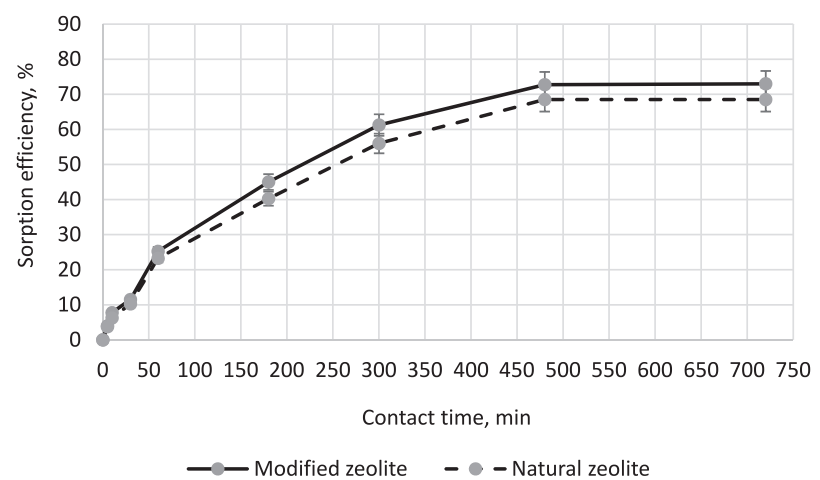

Fig. 2. Sorption efficiency comparison between natural and modified zeolite in $4 \mathrm{mg} / \mathrm{l}$ formaldehyde solution.

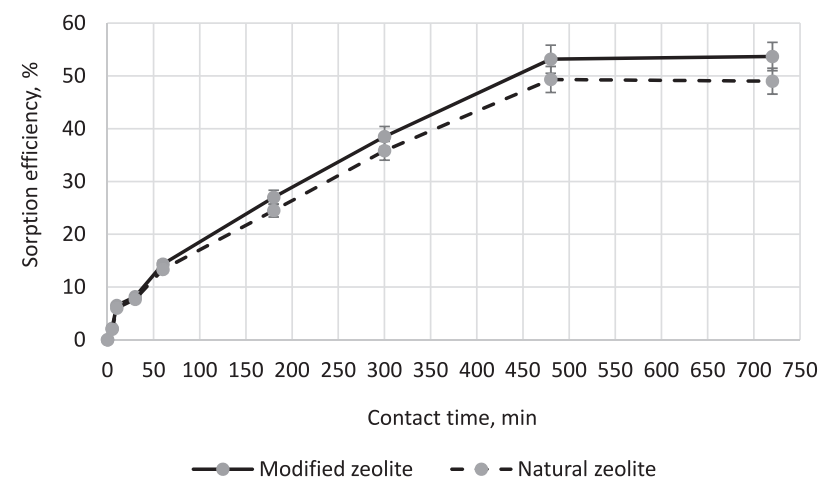

Fig. 3. Sorption efficiency comparison between natural and modified zeolite in $6 \mathrm{mg} / \mathrm{l}$ formaldehyde solution.
Fig. 3 shows sorption efficiency comparison between natural and modified zeolite in $6 \mathrm{mg} / \mathrm{l}$ formaldehyde solution. In this concentration of formaldehyde solution, the observed tendency was the same with a sorption efficiency higher when zeolite was modified with sulphuric acid. After 8-12 hours, when sorption efficiency was highest, modified zeolite reached $53.7 \%$ efficiency, whereas the efficiency of natural zeolite was $49.3 \%$. Therefore, modification of natural zeolite increased sorption efficiency.

Fig. 4 shows a sorption efficiency comparison between natural and modified zeolite in $10 \mathrm{mg} / \mathrm{l}$ formaldehyde solution. As can be seen, modified zeolite reached higher sorption efficiency than natural zeolite. The same tendency was observed for the lower concentration (i.e., 2, 4, and 6 $\mathrm{mg} / \mathrm{l}$ ) of formaldehyde solutions. After 8-12 hours, when sorption efficiency was highest, modified zeolite reached $32.2 \%$ of efficiency, whereas the efficiency of natural zeolite was $30.2 \%$. Therefore, modification of natural zeolite increased sorption efficiency.

After 8-12 hours, when sorption efficiency was highest, modified zeolite reached $21.4 \%$ efficiency and natural zeolite $19.7 \%$ efficiency; modification of natural zeolite increased sorption efficiency. Fig. 5 shows sorption efficiency comparison between natural and modified zeolite in $20 \mathrm{mg} / \mathrm{l}$ formaldehyde solution. In this solution sorption efficiency was the lowest because of the

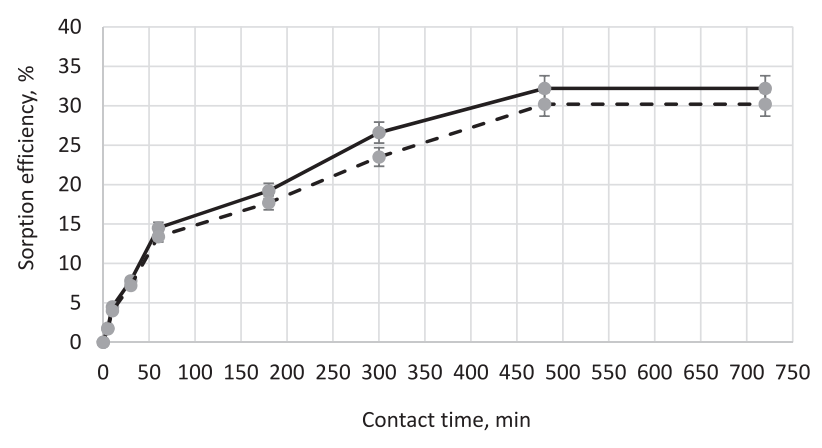

$\longrightarrow$ Modified zeolite $\quad-\bullet-$ Natural zeolite

Fig. 4. Sorption efficiency comparison between natural and modified zeolite in $10 \mathrm{mg} / \mathrm{l}$ formaldehyde solution.

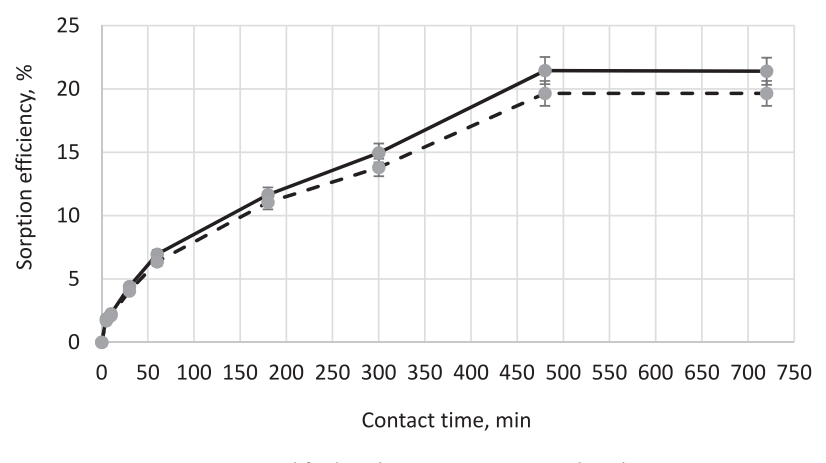

- - Modified zeolite $\quad$ - - Natural zeolite

Fig. 5. Sorption efficiency comparison between natural and modified zeolite in $20 \mathrm{mg} / \mathrm{l}$ formaldehyde solution. 
saturation of zeolite. However, modified zeolite reached higher sorption efficiency than natural zeolite. Modified zeolite reached highest efficiency in $2 \mathrm{mg} / \mathrm{l}$ formaldehyde solution after eight hours of contact time (95.0\%). After longer contact time, sorption did not change because of the saturation of zeolite. In addition, we noted that sorption efficiency decreased when concentration of formaldehyde in solutions was increased. In all cases modified zeolite reached higher sorption efficiency than natural zeolite.

The equilibrium data that are shown in figures 1-5 reveal that the percentage of adsorption efficiency decreased with increases in initial formaldehyde concentration, but the actual amount of formaldehyde adsorbed per unit mass of zeolite increased with increases in formaldehyde concentration, i.e., the adsorption is highly dependent on initial concentration of formaldehyde. This is because at lower concentrations the ratio of the initial number of formaldehyde molecules to the available surface area is low. Subsequently, the fractional adsorption becomes independent from the initial concentration. However, at high concentration the available sites of adsorption becomes fewer and hence the percentage removal of formaldehyde is dependent upon the initial concentration. Equilibrium have established at 8-12 hours for all formaldehyde concentrations. Adsorption capacity of natural zeolite and chemically modified natural zeolite in different formaldehyde solutions is displayed in Table 2. As can be seen in Table 2, the adsorption capacity of zeolite increased when contact time increased. Initial concentration of formaldehyde also affected the adsorption capacity of zeolite. The highest adsorption capacity was reached after 8-12 hours of contact time with a formaldehyde concentration in solution of $20 \mathrm{mg} / \mathrm{l}$.

The adsorption characteristics of any zeolite are dependent upon the detailed chemical/structural makeup of the adsorbent. The $\mathrm{Si} / \mathrm{Al}$ ratio, cation type, number, and location are particularly influential in adsorption. These properties can be changed by several chemical treatments to improve separation efficiency of raw natural zeolite. Acid treatment is used to change the hydrophilic/hydrophobic properties for adsorption of various ions or organics [26].

Chemical treatment can be applied by using acids, bases, or salts. Modified natural zeolites are widely used for wastewater and air treatment [14, 17, 29].

The efficiency of water treatment by adsorbents depends on the type and quantity of the used zeolite, the size distribution of zeolite particles, the initial concentration of contaminants (cation/anion), $\mathrm{pH}$ value of the solution, the ionic strength of the solution, temperature, pressure, contact time of system zeolite/solution, and the presence of other organic compounds and anions. Ion exchange and adsorption properties of natural zeolites in comparison with other chemical processes have the advantage of removing impurities at relatively low levels [23].

According to experimental research results, consistent structural changes were observed for the adsorbent. When

Table 2. Adsorption capacity of natural zeolite and chemically modified natural zeolite in different formaldehyde solutions.

\begin{tabular}{|c|c|c|c|c|c|}
\hline \multicolumn{6}{|c|}{ Natural zeolite } \\
\hline $\begin{array}{c}\text { Contact time, } \\
\min \end{array}$ & $\begin{array}{l}\text { Adsorption capacity, } \\
\mathrm{mg} / \mathrm{g}(2 \mathrm{mg} / \mathrm{l})\end{array}$ & $\begin{array}{l}\text { Adsorption capacity, } \\
\mathrm{mg} / \mathrm{g}(4 \mathrm{mg} / \mathrm{l})\end{array}$ & $\begin{array}{c}\text { Adsorption capacity, } \\
\mathrm{mg} / \mathrm{g}(6 \mathrm{mg} / \mathrm{l})\end{array}$ & $\begin{array}{l}\text { Adsorption capacity, } \\
\mathrm{mg} / \mathrm{g}(10 \mathrm{mg} / \mathrm{l})\end{array}$ & $\begin{array}{c}\text { Adsorption capacity, } \\
\mathrm{mg} / \mathrm{g}(20 \mathrm{mg} / \mathrm{l})\end{array}$ \\
\hline 5 & 0.011 & 0.015 & 0.012 & 0.017 & 0.034 \\
\hline 10 & 0.028 & 0.025 & 0.036 & 0.040 & 0.042 \\
\hline 30 & 0.043 & 0.041 & 0.046 & 0.072 & 0.081 \\
\hline 60 & 0.048 & 0.093 & 0.08 & 0.134 & 0.127 \\
\hline 180 & 0.106 & 0.161 & 0.147 & 0.177 & 0.221 \\
\hline 300 & 0.165 & 0.224 & 0.215 & 0.235 & 0.276 \\
\hline 480 & 0.166 & 0.274 & 0.296 & 0.302 & 0.393 \\
\hline 720 & 0.169 & 0.274 & 0.294 & 0.302 & 0.393 \\
\hline \multicolumn{6}{|c|}{ Chemically modified natural zeolite } \\
\hline 5 & 0.012 & 0.016 & 0.013 & 0.018 & 0.037 \\
\hline 10 & 0.03 & 0.031 & 0.039 & 0.045 & 0.045 \\
\hline 30 & 0.047 & 0.046 & 0.049 & 0.078 & 0.088 \\
\hline 60 & 0.051 & 0.101 & 0.086 & 0.145 & 0.139 \\
\hline 180 & 0.12 & 0.18 & 0.162 & 0.192 & 0.233 \\
\hline 300 & 0.183 & 0.245 & 0.231 & 0.266 & 0.299 \\
\hline 480 & 0.19 & 0.291 & 0.319 & 0.322 & 0.429 \\
\hline 720 & 0.19 & 0.292 & 0.322 & 0.322 & 0.428 \\
\hline
\end{tabular}


an adsorbent sample was treated by $2 \mathrm{M}$ sulphuric acid, its specific surface area and pore volume grew. The acid treatment gives more active adsorptive centers, which enhances adsorption of substances.

The iodine number is a technique employed to determine the adsorption capacity of an adsorbent. The iodine number indicates the porosity of the adsorbent and it is defined as the amount of iodine adsorbed by $1 \mathrm{~g}$ of adsorbent at the $\mathrm{mg}$ level. An iodine number can be used as an approximation for surface area and microporosity of adsorbent with good precision. Iodine adsorption was determined using the sodium thiosulfate volumetric method. It is a measure of activity level (a higher number indicates a higher degree of activation), often reported in $\mathrm{mg} / \mathrm{g}$. It is a measure of the micropore content of the adsorbent by adsorption of iodine from solution [29]. Iodine number before sorption was $154.3 \mathrm{mg} / \mathrm{g}$, and after modification was $164.5 \mathrm{mg} / \mathrm{g}$. Kurama et al. [30] investigated the conversion of a natural Turkish clinoptilolite to hydrogen form by direct treatment with $\mathrm{HCl}$. They found that the ion exchange with $\mathrm{H}^{+}$has a great influence on the effective pore volume and surface area of clinoptilolite. The pore volume and surface area are increased from 0.13 to $0.25 \mathrm{ml} / \mathrm{g}$ and from 35 to $315 \mathrm{~m}^{2} / \mathrm{g}$, respectively.

\section{Conclusions}

1. Determined sorption efficiency after 8-12 hours applying natural zeolite consisting of clinoptilolite and mordenite minerals (Sokirnica Mine, Ukraine) was highest when formaldehyde concentration was lowest, e.g., $2 \mathrm{mg} / 1$ (84.5\%). The lowest sorption efficiency was in $20 \mathrm{mg} / \mathrm{l}$ solution of formaldehyde (19.7\%).

2. Determined sorption efficiency after 8-12 hours applying chemically modified zeolite was highest when formaldehyde concentration was lowest, e.g., $2 \mathrm{mg} / 1(95.0 \%)$. The lowest sorption efficiency was in $20 \mathrm{mg} / \mathrm{l}$ solution of formaldehyde $(21.4 \%)$. The positive effect of natural zeolite chemical modification was obtained in the range of 5.4 to $24.0 \%$, with an average value of $9.2 \%$.

3. Sorption efficiency increases with increasing of contact time with zeolite. The lowest average sorption efficiency was after five minutes and the highest after 8-12 hours, when the adsorption process reached equilibrium.

4. Iodine number was selected as a parameter for natural zeolite chemical modification with $2 \mathrm{M}$ sulphuric acid evaluation. Iodine number before sorption was $154.3 \mathrm{mg} \cdot \mathrm{g}^{-1}$ and after modification was $164.5 \mathrm{mg} \cdot \mathrm{g}^{-1}$.

\section{References}

1. GUIMARAES J.R., FARAH C.R.T., MANIERO M.G., FADINI P.S. Degradation of formaldehyde by advanced oxidation processes. Journal of environmental management, 107, 101, 2012.
2. MOUSSAVI G., YAZDANBAKHSH A., HEIDARIZAD M. The removal of formaldehyde from concentrated synthetic wastewater using $\mathrm{O}_{3} / \mathrm{MgO} / \mathrm{H}_{2} \mathrm{O}_{2}$ process integrated with the biological treatment. Journal of Hazardous Materials, 171, 913, 2009.

3. BOONAMNUAYVITAYA V., SRISUDA S., TANTHAPANICHAKOON W. Preparation of activated carbons from coffee residue for the adsorption of formaldehyde. Separation and purification technology, 42, (2), 168, 2005.

4. ALI I., ASIM M., KHAN T.A. Low cost adsorbents for the removal of organic pollutants from wastewater. Journal of environmental management, 113, 183, 2012.

5. SALMAN M., ATHAR M., SHAFIQUE U., REHMAN R., AMEER S., ALI S. Z., AZEEM M. Removal of formaldehyde from aqueous solution by adsorption on kaolin and bentonite: a comparative study. Turkish Journal of Engineering and Environmental Sciences, 36 (3), 270, 2012.

6. TECH J.E.T. Evaluation of Formaldehyde Adsorption by Human Hair and Sheep Wool in Industrial Wastewater with High Concentration. Journal of Environmental Treatment Techniques, 2 (1), 17, 2014.

7. WANG Z., ZHONG, M., CHEN, L. Coal-based granular activated carbon loaded with $\mathrm{MnO}_{2}$ as an efficient adsorbent for removing formaldehyde from aqueous solution. Desalination and Water Treatment, (ahead-of-print), 11, 2015.

8. ZIELIŃSKI M., DĘBOWSKI M., DUDEK M., GRALA A. Effect of the application of advanced oxidation technology on the effectiveness of anaerobic treatment of wastewaters with a high concentration of formaldehyde. Archives of Environmental Protection, 39 (4), 91, 2013.

9. JARUSUTTHIRAK C., SANGSAWANG K., MATTARAJ, S., JIRARATANANON R. Treatment of formaldehydecontaining wastewater using membrane bioreactor. Journal of Environmental Engineering, 138 (3), 271, 2011.

10. AHMADI M., AMIRI H., MARTÍNEZ S.S. Treatment of phenol-formaldehyde resin manufacturing wastewater by the electrocoagulation process. Desalination and Water Treatment, 39 (1-3), 181, 2012.

11. SALINAS-HERNÁNDEZ C., DÍAZ-NAVA M.C., SOLACHE-RÍOS M. Sorption and desorption of red 5 and yellow 6 by a Fe-zeolitic tuff. Water, Air and Soil Pollution, 223 (8), 4968, 2012.

12. Zhang H., Hu X. Adsorption of Ceftazidime from Aqueous Solution by Multi-Walled Carbon Nanotubes. Polish journal of environmental studies, 24 (5), 2293, 24, 2015.

13. DELLE SITE A. Factors affecting sorption of organic compounds in natural sorbent/water systems and sorption coefficients for selected pollutants. A review. Journal of Physical and Chemical Reference Data, 30 (1), 439, 2001.

14. ALSHAMERI A., IBRAHIM A., ASSABRI A. M., LEI X., WANG H., YAN C. The investigation into the ammonium removal performance of Yemeni natural zeolite: Modification, ion exchange mechanism, and thermodynamics. Powder Technology, 258, 31, 2014.

15. Zeolites-main active components-clinoptilolite and montmorillonite. Accessed 1 August 2015, <http:// www.elega.lt/en/about-products/zeolites-main-activecomponents-clinoptilolite-and-montmorillonite>.

16. HRISTOV P., YOLEVA A., ST DJAMBAZOV I. C., DIMITROV D. Preparation and characterization of porous ceramic membranes for micro-filtration from natural zeolite. Journal of the University of Chemical Technology and Metallurgy, 47 (4), 480, 2012.

17. SHADRIKOV A.S., PETUKHOV A.D. Natural zeoliteclinoptilolite characteristics determination and modification. Вісник Національного університету, 781, 167, 2014. 
18. ANISIMOVA R., BRANNVALL E., PALIULIS D., JASKELEVIČIUS B. Experimental investigation and analysis of using natural zeolite for heavy metal sorption from aquatic solutions. Journal of Environmental Engineering and Landscape Management, 12 (2), 72, 2004 [In Lithuanian].

19. WIDIASTUTI N., WU H., MING A.H., ZHANG D. Removal of ammonium from grey water using natural zeolite. Desalination, 277 (1-3), 229, 2011.

20. OLIVEIRA C.R., RUBIO J. New basis for adsorption of ionic pollutants onto modified zeolites. Minerals Engineering, 20 (6), 558, 2007.

21. BOGDANOV B., GEORGIEV D., ANGELOVA K., YANEVA K. Natural zeolites: clinoptilolite review. In International Science Conference, Stara Zagora, 4-5, 2009.

22. VENGRIS T., BINKIENE R., SVEIKAUSKAITE A. Nickel, copper and zinc removal from waste water by a modified clay sorbent. Applied Clay Science, 18 (3), 190, 2001.

23. MARGETA K., FARKAS A., ŠILJEG M., LOGAR N.Z. Natural Zeolites in Water Treatment-How Effective is Their Use. INTECH Open Access Publisher. 2003.

24. БЕЛЬЧИНСКАЯ Л.И., СТРЕЛЬНИКОВА О.Ю., ХОДОСОВА Н.А., РЕССНЕР Ф. Adsorption-structural, ion exchange and catalytic characteristics of natural and modified sorbent of Sokyrnytsky deposit. Chemistry, physics and technology of surface, 4 (4), 426, 2013 [In Russian].

25. SAKA C. BET, TG-DTG, FT-IR, SEM, iodine number analysis and preparation of activated carbon from acorn shell by chemical activation with $\mathrm{ZnCl} 2$. Journal of Analytical and Applied Pyrolysis, 95, 24, 2012.

26. WANG S., PENG Y. Natural zeolites as effective adsorbents in water and wastewater treatment. Chemical Engineering Journal, 156 (1), 24, 2010.

27. KUČIĆ D., MARKIĆ M., BRIŠKI F. Ammonium adsorption on natural zeolite (clinoptilolite): adsorption isotherms and kinetics modelling. The Holistic Approach to Environment, 2 (4), 158, 2012.

28. ARIVOLI S., HEMA M., PARTHASARATHY S., MANJU N. Adsorption dynamics of methylene blue by acid activated carbon. J. Chem. Pharm. Res, 2 (5), 641, 2010.

29. WANG Z.H., TAO S.J., YU F.J., LI Y.J. Modification of Natural Zeolite and Its Adsorption of $\mathrm{Pb} \sim(2+)$ and $\mathrm{Cu} \sim(2+)$ [J]. Journal of Northeastern University (Natural Science), 11, 30, 2012.

30. KURAMA H., ZIMMER A., RESCHETILOWSKI W. Chemical modification effect on the sorption capacities of natural clinoptilolite. Chemical engineering and technology, 25 (3), 305, 2002. 
